\title{
A construção de um novo paradigma educacional e sua relação com as tecnologias de informação e comunicação
}

\section{The construction of a new educational paradigm and its relationship with information and communication technologies}

\author{
Rosana Souza de Vargas (rosanasdvargas@gmail.com) \\ Mestranda do Programa de Pós-Graduação Strictu Sensu em Educação nas Ciências, Universidade \\ Regional do Noroeste do Estado do Rio Grande do Sul \\ Maria Cristina Pansera de Araújo (pansera@unijui.edu.br) \\ Professora do Programa de Pós-Graduação Strictu Sensu em Educação nas Ciências, Universidade \\ Regional do Noroeste do Estado do Rio Grande do Sul
}

\begin{abstract}
Resumo:
Atualmente, a racionalidade técnica é, ainda, a teoria do currículo reconhecida como o paradigma educacional vigente, nas esferas educativas. Contudo, as crescentes discussões acerca das tecnologias de informação e comunicação como instrumentos culturais, sob o prisma da teoria histórico-cultural vigotskiniana, como ferramentas de mediação, põem em pauta a argumentação de que o paradigma educacional emergente está se constituindo. Desse modo, para além de realizar uma revisão bibliográfica sobre o conceito de paradigma e sobre o que representa esse paradigma emergente e em que termos se pauta, o objetivo deste trabalho é investigar a produção em relação aos avanços teóricos, que envolvem a temática, no portal de periódicos da CAPES. As interlocuções teóricas foram realizadas a partir dos conceitos de paradigmas e de paradigmas educacionais. A metodologia adotada é a Análise Textual Discursiva (MORAES; GALIAZZI, 2013). Os trabalhos publicados tratam de discussões teóricas que apresentam as TIC como ferramentas culturais essenciais para se estabelecer uma mudança concisa de paradigma. Com isso, concluímos que é preciso investimento em formação continuada visando explorar as potencialidades pedagógicas e cognitivas possibilitadas pelas TIC, para que professores e alunos tenham uma formação integral cidadã autônoma, crítica e reflexiva.
\end{abstract}

Palavras-chave: análise textual discursiva; currículo; formação de professores; TIC.

\begin{abstract}
:
Nowadays, technical rationality is still the theory of the curriculum recognized as the current educational paradigm in the educatives spheres. However, the growing discussions about information and communication technologies as cultural instruments, under the prism of Vygotskin's historical-cultural theory, as mediation tools, put into question the argument that the emerging educational paradigm is being constituted. Thus, in addition to carrying out a bibliographic review on the concept of paradigm and on what this emerging paradigm represents and on what terms it is based, the objective
\end{abstract}


of this work is to investigate current production in relation to theoretical advances, which involve the theme, in CAPES journals portal. The theoretical interlocutions were made from the concepts of paradigms and educational paradigms. The adopted methodology is the Discursive Textual Analysis (Moraes; Galiazzi, 2013). The published works deal with theoretical discussions that present ICT as essential cultural tools to establish a concise paradigm change. With this, we conclude that investment in continuing education is necessary in order to explore the pedagogical and cognitive potentialities made possible by ICT, so that teachers and students have an autonomous, critical and reflective integral education.

Keywords: ICT; discursive textual analysis; curriculum; teacher training.

\section{INTRODUÇÃO}

A educação enfrenta de forma constante os desafios da atual era digital, onde as tecnologias de informação e comunicação (doravante TIC) irrompem como importantes elementos de (re)organização dos currículos escolares, das práticas docentes e da formação de professores. Assim, no âmbito educacional, tem-se discutido, amplamente, nas várias instâncias sociológicas, filosóficas, de ordem política, por meio de legislações e documentos legais, que visam argumentar a favor de um ensino democrático, interacionista e comunicativo, pautado na formação de cidadãos ${ }^{1}$ críticos e reflexivos.

O debate acerca do ensino tradicional, centrado na racionalidade técnica, na simples transmissão e assimilação de saberes, em que o professor é o único detentor do conhecimento e, o aluno um ser passivo no processo de ensino e aprendizagem (FREIRE, 2008), perde lugar diante das demandas da sociedade contemporânea, impulsionadas pela globalização e pelas TIC.

Desse modo, os paradigmas epistemológicos educacionais, que se constituíram historicamente, persistem até hoje como positivistas, tecnicistas e instrucionais, que não consideram o aluno e suas especificidades, nem a dialogicidade e a comunicação, como princípios educativos, muito menos uma formação humanista (FREIRE, 2008;

\footnotetext{
${ }^{1}$ Ao falar em questões cidadãs, queremos salientar que o nosso entendimento acerca da dimensão ética do trabalho docente pressupõe um ensino que seja significativo, completo de sentido, assumindo a escola como um ambiente de ensino sobre a humanidade e sobre os sujeitos que nela vivem, construindo, deste modo, os fundamentos essenciais para a constituição do conhecimento, almejando que o aluno construa um entendimento de mundo que seja próprio de si, assumindo suas ações e exercendo-as por meio de práticas reflexivas, autônomas, críticas, questionadoras, responsáveis com o meio sociocultural.
} 
MACEDO; LOPES, 2011). No entanto, autores como Paulo Freire (2008) e Moraes (1996) defendem um ideal de educação e de processos de ensino e aprendizagem, que envolva o aluno como sujeito ativo, ao contrário do que vem ocorrendo; um ensino que considere o contexto dele, suas potencialidades e capacidades. A partir disso, é possível compreender a constituição de um novo paradigma educacional em contraposição ao da racionalidade técnica, conforme propõem Moraes (1996), Behrens (2013), Behrens e Simas (2019), entre outros.

Nesse sentido, outra discussão, que ganha forças, ocorre acerca das TIC e sua inserção na educação, principalmente, e desde a constituição desse novo paradigma. Desde sua evolução, o desenvolvimento tecnológico digital demonstra-se cada vez mais crescente em todas as instâncias da sociedade, de maneira mais didática e interativa na educação, tanto em termos de qualidade e quantidade quanto variedade. As TIC, vistas sob o prisma da teoria histórico-cultural vigotskiniana (KURTZ; VARGAS; MOURA, 2018), inserem-se como instrumentos/ferramentas culturais presentes em nosso cotidiano e que possibilitam diferentes relações entre as pessoas, transformando o modo de interagir, o sistema biológico e o pensamento cognitivo dos seres humanos, constituindo novas características, valores sociais, culturais e educacionais.

Contudo, buscar o envolvimento com TIC, nas salas de aula, pode não significar uma quebra dos paradigmas tradicionais, visto que utilizá-las, per si, não implica em mudança de metodologias ou abordagens teóricas, mas talvez, num processo "mascarado" (MORAES, 1996). Assim, realizar uma revisão de paradigma educacional emergente e sua relação com o advento tecnológico digital, implica entender o próprio conceito de paradigma e o que ele representa, nos marcos educacionais, na medida em que passa a desestabilizar a própria estrutura epistemológica, que dita a fonte de valores e verdades sociais e universais, a partir da ciência positivista. Com tais colocações, o presente trabalho tem como objetivo investigar e compreender como ocorre a discussão teórica em relação ao novo paradigma educacional relacionado às temáticas de TIC, por meio de uma pesquisa realizada no portal de periódicos da CAPES. Buscamos também discutir brevemente e explicar o que constitui um paradigma (KUHN, 1998), e quais as bases para tal discussão, numa revisão dos novos paradigmas educacionais ou 
emergentes e sua ligação com as TIC na educação, a partir de Moraes (1996), Behrens (2005), Simas e Behrens (2019).

Interessa-nos, portanto, buscar compreender como ocorre a discussão acerca do novo paradigma educacional, para investigar se os trabalhos publicados, em sua maioria, são teóricos e/ou empíricos e qual sua relevância social e acadêmica. Além de buscar defender um ensino, que proponha uma nova avaliação dos paradigmas emergentes e em relação aos tradicionais, visando a inserção das TIC em metodologias condizentes com o contexto atual da educação.

\section{PARADIGMA DE THOMAS KUHN E SUA REPERCUSSÃO NOS PARADIGMAS EDUCACIONAIS - 0 TRADICIONAL E O EMERGENTE}

O termo paradigma é uma palavra de origem grega: paradeigma, que tem seu significado naquilo que conhecemos por modelo. Thomas Kuhn (1998, p. 29), ao cunhar o termo afirma que o mesmo diz respeito a um "conjunto de crenças, valores e técnicas comuns a um grupo que prática um mesmo tipo de conhecimento". A teoria de Kuhn pela qual a ciência progride baseia-se, principalmente, na estrutura ciência normal, crise, revolução.

Os cientistas que trabalham dentro de um paradigma praticam o que Kuhn chama de ciência normal. Essa ciência, de acordo com o autor, "é baseada no pressuposto de que a comunidade científica sabe como é o mundo" (KUHN, 1998, p. 24). Assim, os cientistas normais explicam e adequam o paradigma aos comportamentos desse mundo, e "frequentemente suprimem novidades fundamentais, porque estas subvertem necessariamente seus compromissos básicos" (KUHN, 1998, p. 24). Segundo Kuhn (1998), o que diferencia uma ciência normal da não-ciência é a existência de um paradigma capaz de sustentar uma tradição.

Quando ocorre um problema que não segue as regras do paradigma, ou que não pode ser enquadrado nele, ou seja, quando não se encontram solução para solucioná-lo ele passa a ser visto como uma anomalia (KUHN, 1998). Segundo o autor, essa anomalia leva ao fracasso e uma quebra nas expectativas, provocando uma crise na 
ciência normal. A crise consiste na persistência de problemas não solucionados, o que ocasiona o descontentamento e inquietude dos cientistas normais, enfraquecendo o paradigma e sua validade científica, e passa a indicar que é "chegada a ocasião para renovar os instrumentos" (KUHN, 1998, p. 105).

Com isso, se chega ao momento necessário de uma revolução científica, que diz respeito ao abandono de um paradigma e a adoção de um novo. Além disso, esse abandono deve se dar por toda a comunidade científica; após a teoria científica adotar o status de paradigma, somente será inválida quando todo esse processo ocorrer de novo, ou seja, quando houver uma alternativa para substituí-la (KUHN, 1998).

Com base nessas informações, de acordo com Behrens (2013), o paradigma newtoniano-cartesiano, chamado assim por se fundamentar, principalmente, nas teorias de Newton (1643-1727), Galileu Galilei (1564-1642) e Descartes (1596-1650), é o que mais influência as práticas da sociedade atual. Tal concepção compreende um método analítico e de raciocínio lógico-dedutivo que, a partir de seu alicerce na razão, "separa natureza e pessoa humana, mente/matéria e corpo/mente", e valoriza "a especialização, a atomização, a compartimentalização do conhecimento, a racionalidade instrumental científica hegemônica" (SIMAS; BEHRENS, 2019, p. 180).

Com acentuada influência nos processos pedagógicos, e baseada nos pressupostos desse paradigma, a ciência acaba por influenciar a Educação com um pensamento de reprodução de conhecimento que é fragmentado, mecanizado, técnico, que ocorre a partir de uma ideia reducionista (BEHRENS, 2013). Por essa lógica, o objeto de estudo e seu entendimento ocorre das partes para o todo e o contexto não é relevado nem percebido (BEHRENS, 2013; SIMAS, BEHRENS, 2019). De acordo com Simas e Behrens (2019, p. 180), esse paradigma separou o "conhecimento científico e conhecimento proveniente de senso comum, fragmentando, compartimentalizando o pensamento, separando o conhecimento em disciplinas estanques e isoladas".

Nesse paradigma tradicional da educação, o centro está em torno da transmissão de conhecimento feito pelo professor, único detentor, por meio de aulas expositivas, em que o aluno é considerado um ser passivo, não questionador, com foco no ensino e não na aprendizagem (BEHRENS, 2013). Como bem ressalta Moraes (1996, p. 59), “o velho modelo da ciência positivista vem influenciando a Educação, há mais de 300 
anos", a partir da associação de "várias correntes de pensamento da cultura ocidental, dentre elas, a Revolução Científica, o Iluminismo e a Revolução Industrial, que estiveram presentes a partir dos séculos XVII, XVIII e XIX". A datar dessa época, todas as concepções epistemológicas e filosófica-positivistas começaram a ser aplicadas em fenômenos sociais como se fossem algo natural e aplicável a qualquer contexto (MORAES, 1996).

Por isso, Moraes (1996) ressalta que o grande problema da educação é decorrente desse modelo de ciência, que prevaleceu nesse certo momento histórico, influenciando uma visão fragmentada dos processos de ensino e aprendizagem, marcando abordagens e práticas pedagógicas que não condizem mais com os dias atuais.

Com isso, a visão de um novo paradigma começou a se formar, juntamente com a nova percepção, que se tinha sobre o mundo. Nessa visão, "todos os conceitos, todas as teorias e as descobertas têm um caráter limitado e são aproximadas" (MORAES, 1996, p. 61). Assim, a epistemologia absoluta e de uma única verdade encontra-se abalada, a partir da ideia de que se constituem "teorias transitórias", cada vez mais próximas da realidade e de verdades, no plural.

A visão do novo paradigma é de totalidade, em que os pensamentos sistêmicos dos conceitos aplicados à educação sugerem a substituição da "compartimentação por integração, desarticulação por articulação, descontinuidade por continuidade, tanto na parte teórica quanto na práxis da educação" (MORAES, 1996, p. 63). É um modo que desconsidera a compartimentação do conhecimento, presume procedimentos metodológicos adequados aquilo que é da realidade dos sujeitos. Os alunos devem formar-se com uma concepção indivisa, construindo seu conhecimento com razão, intuição, emoções e sensações; o que consequentemente, permitirá uma visão mais ampla do contexto, do mundo e da vida, especialmente, por meio de um diálogo entre esses, entre sujeito e objeto (MORAES, 1996).

Como o aluno aprende a aprender? Como ensinar essa prática? A resposta, de acordo com Moraes (1996, p. 64), está na capacidade de "refletir, analisar e tomar consciência do que sabe, dispor-se a mudar os próprios conceitos, buscar novas informações, substituir velhas "verdades" por teorias transitórias", e adquirir os novos conhecimentos que resultam da evolução das TIC. Há muito tempo, Manuel Castells, 
em sua obra A sociedade em rede (1999), cunhou o termo, altamente reconhecido até hoje, para denominar o cenário em que a sociedade se baseia, o qual chamou de "paradigma da tecnologia da informação".

A partir desse termo, a informação constitui-se como parte integral da atividade do homem e, deste modo, todos os processos tocantes à sua existência, seja na esfera individual ou coletiva, se moldam pelo meio tecnológico digital. Esse paradigma influencia os processos pedagógicos. Moraes (1996) ressalta que a matriz educacional é entendida como uma escola expandida, que une diferentes classes sociais. A partir dessas ferramentas tecnológicas, a escola não se encontra mais limitada às suas paredes, o que abre espaço para a comunidade como um todo.

Há um processo mais amplo para o compartilhamento do conhecimento, o que implica poder afirmar que os sujeitos precisam ser letrados no uso das ferramentas digitais, produzindo, analisando, interagindo e criando novas formas de representar os conhecimentos de maneira crítica e imaginativa. Por meio do envolvimento com tais ferramentas, é possível trabalhar com o aluno a autonomia, a organização, concentração e motivação, pensando sempre em processos de ensino e aprendizagem com qualidade e equidade (MORAES, 1996).

Moraes (1996), quando afirma que o novo paradigma é construtivista, interacionista, sociocultural e transcendente, fala desses moldes. Em uma perspectiva tecnológica e considerando a teoria histórico-cultural e o sociointeracionismo de Vigotski, a partir do que está posto por neo-vigotskinianos como Wertsch (2002), as ferramentas digitais são parte da cultura humana, foram criadas a partir do pensamento humano e, não obstante, são mediadoras dos processos de interação entre as pessoas, umas com as outras e entre elas com o conhecimento, modificando os seres não só biologicamente, mas também psicologicamente e intelectualmente/cognitivamente.

Assim, de acordo com Wertsch (2002), Miranda (2007), Jonassen (2000), Kurtz, Vargas e Moura (2018), as TIC são consideradas como ferramentas cognitivas de pensamento, que implicam em novas formas de pensar dos alunos, não lhes cabendo mais o nome de "auxiliares de ensino". Por isso, a ideia não é simplesmente "mascarar" uma nova forma de ensinar, mas sim, realmente compor práticas efetivas, que constituam a base para uma formação crítica e cidadã a partir dessas ferramentas. 
Dessa maneira, as escolhas pedagógicas feitas para a sala de aula, em relação às TIC, podem englobar a criação, pesquisas elaboradas, produção por meio de softwares e ferramentas online, possibilitar aprendizagens mais interativas, problematizadoras e reflexivas. Deste modo, de acordo com Osório, Stoll e Martins (2019, p. 24) "nesses casos, o papel do professor é mediar e auxiliar na condução das atividades e na interpretação das informações disponibilizadas pelos aplicativos". A partir disso, entendemos que é possível cumprir um papel social que resulta em cidadãos ativos, autônomos, críticos e reflexivos, que poderão agir na sociedade conforme aquilo, que aprendem na escola.

Considerando o exposto, apresentaremos a análise, que subsidia o presente trabalho, no sentido de investigar como ocorre a discussão teórica em relação aos novos paradigmas educacionais relacionados às temáticas de TIC.

\section{METODOLOGIA}

Como caminho metodológico, adotamos uma abordagem qualitativa, por meio da análise textual discursiva (ATD) de Moraes e Galiazzi (2013). Para os autores, a ATD "[...] é um processo integrado de análise e de síntese que se propõe a fazer uma leitura rigorosa e aprofundada de conjuntos de materiais textuais", tendo o objetivo de "descrevê-los e interpretá-los no sentido de atingir uma compreensão mais complexa dos fenômenos e dos discursos a partir dos quais foram produzidos" (MORAES; GALIAZZI, 2013, p. 112). Assim, a ATD pode ser entendida como:

[...] um processo auto-organizado de construção de compreensão em que novos entendimentos emergem de uma sequência recursiva de três componentes: desconstrução do corpus, a unitarização, o estabelecimento de relações entre os elementos unitários, a categorização, e o captar do novo emergente em que nova compreensão é comunicada e validada (MORAES, 2003, p. 192).

Desse modo, o primeiro critério adotado foi a escolha do Portal da CAPES, onde com a ferramenta de busca avançada do site, colocamos os descritores "paradigmas educacionais emergentes" e "tecnologias de informação e comunicação", que identificaram 238 trabalhos. Não foi adotado critério de busca relacionado ao ano de publicação, mas sim ao tipo; apenas artigos completos, com a exclusão de trabalhos 
acadêmicos como teses, dissertações e capítulos de livros. Primeiramente, foi feita uma análise dos 238 trabalhos, considerando o título, as palavras-chave e o resumo, chegando ao final com 18 trabalhados selecionados, escolhidos por apresentar escritas relevantes para o objetivo dessa pesquisa, além de conter o descritor "tecnologias de informação e comunicação" (com algum tipo de abordagem epistemológica) ou ambos, "paradigmas educacionais emergentes" e "tecnologias de informação e comunicação".

O Quadro 1 apresenta a sistematização dos trabalhos consultando o, abaixo exposto.

Quadro 1 - Artigos selecionados como corpus de análise.

\begin{tabular}{|c|c|c|}
\hline \multirow[b]{2}{*}{ Dados dos artigos encontrados } & \multicolumn{2}{|c|}{ Descritores de seleção } \\
\hline & Tipo de discussão & $\begin{array}{l}\text { Menções a } \\
\text { paradigmas } \\
\text { educacionais }\end{array}$ \\
\hline $\begin{array}{l}\text { ALMEIDA FILHO, C. C. P. de. O avanço da } \\
\text { educação a distância no brasil e a quebra de } \\
\text { preconceitos: uma questão de adaptação. Revista } \\
\text { Multitexto, v. } 3 \text {, n. } 01, \text { p. } 14-20,2015 \text {. }\end{array}$ & teórica. & 3 \\
\hline $\begin{array}{l}\text { ALMEIDA, F. M. de. Aprendizagem em Rede, as } \\
\text { novas tecnologias e a alfabetização tecnológica do } \\
\text { professor. Observatório Journal, v. 4, n. } 2 \text { p. } 035- \\
055,2010 \text {. }\end{array}$ & teórica & 9 \\
\hline $\begin{array}{l}\text { BITANTE, A. P. et al. Impactos da tecnologia da } \\
\text { informação e comunicação na aprendizagem dos } \\
\text { alunos em escolas públicas de São Caetano Do Sul } \\
\text { (SP). Holos, n. } 32 \text {, v. } 08,2016\end{array}$ & teórica e prática & 2 \\
\hline $\begin{array}{l}\text { CALIARI, K. V. Z.; ZILBER, M. A.; PEREZ, C. } \\
\text { Tecnologias da informação e comunicação como } \\
\text { inovação no ensino superior presencial: uma análise } \\
\text { das variáveis que influenciam na sua adoção. REGE } \\
\text { - Revista de Gestão, n. } 24 \text {, p. } 247-255,2017\end{array}$ & teórica e prática. & 1 \\
\hline $\begin{array}{l}\text { CAMPOS, F. A convergência como tendência para } \\
\text { a educação do Presente. Revista Saber e Educar, n. } \\
25,2018 \text {. }\end{array}$ & teórica & 3 \\
\hline $\begin{array}{l}\text { CUNHA, A. de L. da. O professor de Matemática } \\
\text { do ensino médio e as tecnologias de informação e } \\
\text { comunicação nas escolas públicas estaduais de } \\
\text { Goiás. RISTI, n. } 4,2015 \text {. }\end{array}$ & teórica e prática. & 2 \\
\hline $\begin{array}{l}\text { ESCOLA, J. J. J. Aplicações das TIC no Ensino da } \\
\text { Educação Física. Revista Retos, Lisboa, n. } 34 \text {, } \\
\text { p.371-376, 2018. }\end{array}$ & teórica & 1 \\
\hline $\begin{array}{l}\text { LOSTADA, L. R; CRUZ, D. M. A EAD como um } \\
\text { horizonte de novas possibilidades didático- } \\
\text { pedagógicas: o caso do curso de especialização em } \\
\text { educação na cultura digital. Poiésis, Tubarão, v.11, }\end{array}$ & teórica e prática. & 4 \\
\hline
\end{tabular}




\begin{tabular}{|c|c|c|}
\hline n. 19, p. $188-208,2017$ & & \\
\hline $\begin{array}{l}\text { MARQUES, G. da C.; CAVALCANTI, C. C. } \\
\text { Educação a distância na universidade de São Paulo: } \\
\text { desafios no processo de implantação de um novo } \\
\text { modelo educacional. Educação temática digital, } \\
\text { Campinas, v. } 10, \text { n. } 2 \text {, p. } 37-53,2009 \text {. }\end{array}$ & teórica & 3 \\
\hline $\begin{array}{l}\text { MENDONÇA, E. T. de. et al. Paradigmas e } \\
\text { tendências do ensino universitário: a metodologia } \\
\text { da pesquisa-ação como estratégica de formação } \\
\text { docente. Interface Botucatu, n. 19, v. 53, p. 373-86, } \\
2015 \text {. }\end{array}$ & teórica e prática & 26 \\
\hline $\begin{array}{l}\text { MORAES, S. R. et al. Vídeos e músicas utilizados } \\
\text { como instrumentos motivadores no processo } \\
\text { ensino-aprendizagem. Holos, n. } 31 \text {, v. } 2 \text {, p. 386- } \\
300,2015 \text {. }\end{array}$ & teórica e prática & 1 \\
\hline $\begin{array}{l}\text { NETO, C. E. S.; FREIRE, G. H. A. Ação e } \\
\text { competência em informação para inclusão na } \\
\text { educação: os professores na sociedade em rede. } \\
\text { Revista Prisma, n. } 29, \text { p. } 47-65,2015 \text {. }\end{array}$ & teórica e prática & 2 \\
\hline $\begin{array}{l}\text { NOGARO, A.; BATTESTIN, C. Sentidos e } \\
\text { contornos da inovação na educação. Holos, n. 32, v. } \\
2,2016 .\end{array}$ & teórica & 4 \\
\hline $\begin{array}{l}\text { OLIVEIRA, L. S. C. Apresentação metodológica } \\
\text { com uso de tecnologia digital no ensino de ciências. } \\
\text { Revista Sustinere, Rio de Janeiro, v. } 5 \text {, n. 1, p. 68- } \\
89,2017\end{array}$ & teórica e prática & 3 \\
\hline $\begin{array}{l}\text { ROCHA, A. M. da; BOLZAN, D. P. V. La cultura } \\
\text { de convergência digital y la inclusión sociocultural: } \\
\text { Interconectando formación y práctica docente. } \\
\text { Educatio Siglo XXI, n. 3, v. 33, p. 123-146, } 2015\end{array}$ & teórica e prática. & 6 \\
\hline $\begin{array}{l}\text { RODRIGUES, M. E. P. As redes sociais: } \\
\text { Instrumentos de comunicação no ensino superior. } \\
\text { Cadernos } B A D \text { Portugual, n. 1/2, p. 112-122, } 2013 .\end{array}$ & teórica e prática & 3 \\
\hline $\begin{array}{l}\text { SANTOS, G. L. A promoção da inclusão digital de } \\
\text { professores em exercício: uma pesquisa de síntese } \\
\text { sobre aproximações entre professores, novas mídias } \\
\text { e manifestações culturais emergentes na escola. } \\
\text { Inter-Ação, Goiânia, v. 39, n. 3, p. 529-543, } 2014 \text {. }\end{array}$ & teórica & 2 \\
\hline $\begin{array}{l}\text { SILVA, L. A. da; MACHADO, L. R. de S. } \\
\text { Inovações educacionais versus cultura escolar: as } \\
\text { implicações dos paradigmas de formaçãa docente e } \\
\text { da incorporação do uso pedagógico das TICs aos } \\
\text { processos escolares. Conjectura, Caxias do Sul, v. } \\
\text { 15, n. 2, p. 119-131, 2010 }\end{array}$ & teórica & 10 \\
\hline
\end{tabular}

Fonte: Dados da pesquisa

A partir da ATD realizada, chegamos a duas categorias principais: i) concepções sobre o novo paradigma em construção na sua relação com as TIC, e, ii) importância da formação continuada de professores sobre a função das TIC. Os dados advindos da 
análise serão triangulados com as referências bibliográficas utilizadas, na revisão de literatura deste trabalho apresentada abaixo, a fim de articular de maneira mais basilar os argumentos e metatextos produzidos.

É importante destacar que selecionamos os trechos mais relevantes para a discussão em questão, marcados em itálico, para diferenciar do aporte teórico geral. Algumas expressões foram grifadas em negrito a fim de salientá-las e utilizá-las como argumento para a escolha de unidade em relação as suas categorias e ao aporte teórico utilizado, já as unidades de significado foram identificadas com o nome do autor, ano e página do artigo que contém a unidade citada.

\section{ENTRE RESULTADOS E DISCUSSÕES, A ANÁLISE}

A partir da ATD, identificamos duas categorias principais: i) concepções sobre o novo paradigma em construção na sua relação com as TIC, e, ii) importância da formação continuada para professores. Além do mais, é necessário compreender que os trabalhos categorizados no quadro 1, como "discussão teórica e prática”, em sua grande maioria, discutem análises de entrevistas/questionários com docentes e discentes (BITANTE, 2016; CALIARI; ZILBER; PEREZ, 2017; CUNHA, 2015; NETO; FREIRE, 2015; ROCHA; BOLZAN, 2015; RODRIGUES, 2013), e poucos resultaram de práticas, que envolviam cursos, pesquisa-ação, capacitação, situação de estudo com software/TIC (LOSTADA; CRUZ, 2017; MENDONÇA, 2013; MORAES et al., 2015; OLIVEIRA, 2017).

\subsection{Concepções sobre o paradigma em construção na sua relação com as TIC}

De acordo com o que destacamos na revisão bibliográfica, os artigos lidos apresentaram algum tipo de discussão acerca do paradigma vigente/tradicional e/ou superação do mesmo. Assim, nessa categoria, ressaltamos as seguintes ideias: estamos ainda seguindo um modelo tradicional de ensino em que o professor/escola detém o conhecimento/saber e o aluno é um ser de passividade, que apenas recebe informações, sem produção e ação no seu fazer; o contexto está modificando tais concepções, 
"abrindo alas" para a discussão de um novo paradigma, principalmente a partir do advento das TIC.

Conforme Mendonça et al. (2015, p. 374), “o modelo de ensino predominante, denominado tradicional, caracterizado pela transmissão de conhecimentos, pela ênfase na memorização em detrimento da reflexão crítica" [...] "baseia-se [...] em aulas expositivas, onde o professor é o detentor de conhecimentos e grande protagonista, cabendo, aos estudantes, repetirem fidedignamente os conteúdos memorizados nas provas classificatórias". Desse modo e corroborando com tal ideia, Oliveira (2017, p. 71), aponta que há ainda, atualmente, "uma recorrência a tais modelos de períodos passados e que refletem na insuficiência no ensino [...]".

Silva e Machado (2010, p. 120) dizem que esse modelo "verticalizado de organização da estrutura e do funcionamento dos tempos e espaços escolares [...], ainda teima em se conformar como um dos aspectos delineadores da cultura escolar neste século”. Assim, esses autores, apoiados em Perrenoud assinalam que o cenário quotidiano "da grande maioria das escolas revela que antigos problemas educacionais ainda não foram superados, e que a cultura escolar vigente no século XXI muito pouco se diferencia ou se distancia daquela vigente no século passado" (Ibidem, p. 120).

Ainda, de acordo com Silva e Machado (2010, p. 125), "paradoxalmente, o cenário social desta década apresenta diferenças acentuadas em relação à panorâmica do século passado". Por sua vez, Lostada e Cruz (2017, p. 191) explicam que essa possibilidade de mudança passa "necessariamente pela educação e pela promoção de novos valores, resultando na necessidade de [...] rever as práticas pedagógicas tradicionais, [...] para que gerem um novo modelo de educação e, por consequência, também de sociedade e de indivíduo".

A partir dos excertos encontrados, é possível compreender que o paradigma educacional caracterizado como tradicional ainda se configura e se faz presente nas escolas e nas práticas de professores, no entanto, como veremos a seguir, "começam as investigações extraordinárias que finalmente conduzem a profissão a um novo conjunto de compromissos, a uma nova base para a prática da ciência" (KUHN, 1998, p. 25), que conduzem a outro paradigma. Rodrigues (2013, p. 113) contribui, dizendo que "passouse do paradigma do ensino para o da aprendizagem. Neste novo modelo, o que o 
estudante deve aprender não devem ser só conhecimentos, mas também [...] competências", a partir do qual, a escola deve "possibilitar aos indivíduos [...] um caráter crítico diante do cotidiano, para que se possa relativizar o conhecimento científico diante de suas novas redes de agenciamentos" (LOSTADA; CRUZ, 2017, p. 191).

Assim, estão estabelecidas anomalias no paradigma tradicional que se constituem como crises e que não são mais ignoradas por aqueles que compõem a comunidade educacional, que está insatisfeita com a forma que o sistema ocorre atualmente. Logo, a "emergência de uma nova teoria rompe com uma tradição da prática científica e introduz uma nova dirigida por regras diferentes, situadas no interior de um universo de discurso também diferente" (KUHN, 1998, p. 117). É preciso, então, formar indivíduos, cidadãos para uma prática e visão crítica da sociedade, concebendo e produzindo novos saberes que os levem à sua emancipação; relativizando e desconstruindo conhecimentos perpetuados e entendidos como não questionáveis (MORAES, 1996; BEHRENS, 2013; MORAN, MASSETO, BEHRENS, 2000). Precisa-se compreender, identificar e analisar a razão instrumental tradicional da cultura escolar e modificar as ações; que não se farão mais mecânicas e técnicas, mas ao contrário, humanas e interativas.

Lostada e Cruz (2017, p. 205) salientam que "o cenário cultural contemporâneo evidencia uma verdadeira crise educacional, onde se estabelece um profundo abismo entre aquilo que as pessoas vivenciam e o que ensinam as escolas". Mas, contrariamente, "as novas abordagens do processo de ensino e aprendizagem direcionam" o professor para "um trabalho com novos artifícios que visam estimular $\boldsymbol{e}$ motivar os alunos a participarem do processo [...]. Sendo assim, há muitos recursos que colaboram nesse processo, como as TIC" (OLIVEIRA, 2017, p. 75). Segundo Almeida Filho (2015, p. 14), “o deslocamento até a sala de aula e a figura imponente do professor diante de seus alunos já não é mais a única forma de enxergar o fazer educacional".

Nessa construção, o paradigma tradicional apontado por Moraes (1996) passa a ser desconstruído e não mais suficiente. Estabelece-se, portanto, uma crise nessa ciência escolar que exige novas construções epistemológicas do conhecimento disseminado e 
produzido, nas escolas. O paradigma "velho", por muito tempo fora uma tradição, pois o que o diferenciava era, justamente, as fundações que o sustentavam em determinada época, e que a ela serviam. No entanto, nessa compreensão de quebra de paradigma e reformulação de um novo, conforme ressaltado por Kuhn (1998), o novo paradigma, ou emergente começa a calcar seu espaço como uma ciência normal, começa ele a construir suas bases para mudanças necessárias.

Neto e Freire (2015, p. 50) apontam que com o advento das TIC, “o atual momento marcado pela informação em rede, tem influenciado o comportamento da sociedade em propor novas formas de educação". Para Escola (2018, p. 372), portanto, as rápidas modificações que "o progresso tecnológico introduziu exigem novas capacidades e competências dos educadores passíveis de responder aos desafios dromológicos", promovendo uma grande "aceleração, da velocidade nos dispositivos tecnológicos que, por sua vez, se refletem na ação de ensinar e aprender".

Almeida (2010, p. 51), inclusive, afirma que "se institui o tripé: aprendizagem, tecnologias e metodologias, como fundamentador dessa abordagem educacional que, numa perspectiva construtivista $\boldsymbol{e}$ interacionista, focada no saber compartilhado $e$ colaborativo". Almeida (2010) aponta na nomeação do tripé da educação, sua concordância com o que Moraes (1996) e Behrens (2013) salientam acerca do novo paradigma, mesmo que sem nomear tal feito. A partir dessas ideias "os processos de escolarização pressupõem serem concebidos como mais amplos e alargados em horizontes e possibilidades, ressignificadores dos processos de aprendizagem para a vida" (SIMAS; BEHRENS, 2019, p. 182).

Nesse sentido, é preciso reconhecer o "potencial pedagógico das Tecnologias Digitais de Informação e Comunicação" (SANTOS, 2014, p. 531). Nesse viés, as TIC, conforme Bitante (2016, p. 189-190), devem ser envolvidas no ensino como "ferramenta cognitiva, que não busque somente a informação; mas, também estimule os usuários a acessar, analisar, interpretar e organizar seu conhecimento pessoal com o uso de problemas propostos". Rocha e Bolzan (2015, p. 130) apontam que criando novas estratégias pedagógicas integrando as TIC, com intencionalidade dirigida "das informações na convergência entre dispositivos tecnológicos virtuais e presenciais", pode [...] "imprimir aos processos de aprendizagem a mediação de tecnologias 
cognitivas, - ou seja, [...] como instrumentos de mediação sociocultural (Vygotski, 1993, 1995) nos processos formativos iniciais e ao longo da vida".

Nesse sentido, para essa nova construção, ressalta-se, bem como fazem Wertsch (2002), Moran, Masseto e Behrens (2000), que é essencial compreender as TIC como ferramentas cognitivas de aprendizagem, mediadoras de conhecimento, a partir das quais os envolvidos possam adquirir competências e habilidades de perceber criticamente e influir ativamente na tomada de decisões, na possibilidade de análise, de produção e de invenção de uma nova sociedade e de novos conhecimentos. Kurtz, Vargas e Moura (2018, p. 147) destacam sobre isso, que "as ferramentas cognitivas promovem [...] a aprendizagem significativa, a construção do conhecimento, o pensamento reflexivo".

Em meio a esse contexto, a aprendizagem acontece em torno de uma perspectiva comunicativa, compreensiva, interativa e dialógica (FREIRE, 2008). O aluno passa a se constituir como um aprendiz autônomo, que reflete e constrói, interativa e colaborativamente, em ambientes e redes virtuais/presenciais de aprendizagem, o conhecimento (MORAN, MASSETO E BEHRENS, 2000; MORAES, 1996).

Acreditamos que tais discussões exigem adequação do ensino e mudança de paradigma, quanto mais adeptos dessa "nova ciência" - de uma nova teoria, utilizando os termos de Kuhn (1998), mais facilmente se chegará a uma revolução científica. O paradigma tradicional há muito se perpetuou, no entanto, a partir das revoluções tecnológicas, pelas quais os professores e a escola deixam de ser os únicos com acesso a conhecimentos e informações, o cenário começa a se modificar. Seguindo a perspectiva de Kuhn (1998), esse paradigma já não consegue mais articular os fatos com a teoria, pois a realidade não condiz mais com as teorias outrora preconizadas.

Desse modo, com anseios que nem tão novos assim, os pesquisadores e educadores começam a se movimentar em busca de um novo horizonte da educação, que longe de um plano horizontal, mas sim, que se faz vertical e transversal. Por isso, abaixo, a outra categoria criada e evidenciada por meio da análise, diz respeito exatamente à necessidade de formação continuada para professores em exercício na profissão sobre o envolvimento de TIC nos processos de ensino e aprendizagem como ferramenta cognitiva pedagógica. 


\subsection{A importância da formação continuada de professores sobre a função das TIC}

Esta categoria criada diz respeito aos discursos apontados pelos trabalhos acerca da necessidade de uma formação continuada para professores no tocante às articulações com as TIC enquanto ferramentas pedagógicas de ensino e aprendizagem. Aqui, surge a figura do professor como aquele educa, portanto, a ele deve ser disponibilizada uma formação adequada em relação a novas metodologias que englobem o uso de TIC e que balizem suas práticas pedagógicas de uma maneira que não seja máscara (uso pelo uso).

Neste sentido, de acordo com Cunha (2015, p. 4), "na busca da quebra de paradigma, não basta só conscientizar a sociedade, é preciso formar os educadores". Almeida (2010, p. 39) ressalta que "os professores da educação básica caminham a trôpegos passos na trilha da alfabetização tecnológica”. Tais colocações demonstram que sem formação adequada, não se tem um efetivo resultado de mudanças de paradigma.

Um outro fator destacado por Santos (2014, p. 530), é de que "a maioria dos cursos de formação de professores (Pedagogias e Licenciaturas) sequer oferece disciplinas relacionadas com as tecnologias educativas". Assim, Cunha (2015, p. 5) destaca que "é necessário desenvolver capacidades que possibilite ao professor manusear os aparatos tecnológicos". Assim, se a maioria dos professores em atuação nas escolas e mesmo em universidades, não tem fluência tecnológica, logo, se pode inferir a ideia de que, também, não possuem uma formação continuada adequada para sanar tal problema, logo, não se irá lançar fluência tecnológica se não houverem formações continuadas que deem subsídios para tanto. Bitante (2016, p. 295) ressalta: "a formação continuada do pessoal docente em termos de uso das tecnologias no seu ensino se faz essencial".

Cunha $(2015$, p. 5) aponta que tal preparo deva ocorrer no sentido de que " $o$ domínio do técnico e do pedagógico não deve acontecer de modo [...] separado do outro. Ou seja, não adianta dominar a tecnologia se não se tem a pedagogia de um professor e vice-versa". Dominar a tecnologia não implica em fazer uso efetivo dela, 
por isso discussões acerca de não tentar "mascarar" o ensino, como a que Moraes (1996) levanta, são relevantes para desconstruir as práticas que buscam utilizar tais ferramentas como auxílio superficial e não, de fato, como fonte de produção de conhecimento, reflexão, criticidade, avaliação e análise de informações.

Santos (2014, p. 539) destaca que “o professor é o principal elemento na condução de uma ação educativa eficaz [...] de uma interação dinâmica com as TDICE”, logo, se ele não “dispõe de um arsenal didático adequado para empregar na gestão de situações educativas mediadas por tais tecnologias, essas [...] tendem a ser estáticas e desmotivadoras [...], tanto para os alunos quanto para eles mesmos, os professores".

Conforme Marques e Cavalcanti (2009, p. 44, A9) ressaltam, “não devemos nos surpreender com o fato de que muitos docentes se oponham à utilização das novas tecnologias no âmbito educacional”, pois "isso acontece porque sua formação $\boldsymbol{e}$ atuação estão centradas em aulas presencias e por meio de métodos de transmissão do conhecimento". Inclusive, Kurtz, Vargas e Moura (2018) pressupõem que cursos de formação continuada, que seguem às exigências governamentais e de organizações internacionais, podem representar uma tendência unilateral por meio dos organizadores envolvidos, apresentando apenas uma perspectiva "dentro do universo que é o processo de ensinar e aprender em um contexto permeado por tecnologias" (p. 15).

De acordo com Escola (2018, p. 374) "uma das dificuldades mais sentidas pelos professores prende-se com o facto de que alguns utilizam as TIC, mas não usam metodologias adequadas às mesmas", repetindo os "mesmos erros detectados nos modelos mais tradicionais de ensino". Sobre isso, Behrens (2000, p. 129) salienta que a “a consistência teórica e metodológica do professor para atuar neste novo paradigma depende da proposição de formação continuada, da oportunidade de discutir com seus pares seus sucessos e suas dificuldades", ainda mais "de momentos que contemplem a reflexão sobre a ação pedagógica que venham desencadear novos processos de atuação em sala de aula".

Assim, a exigência de troca de um paradigma, no entanto, não pode ocorrer no vazio e longe da realidade dos professores, nas escolas. É preciso que sejam realizadas formações no sentido de demonstrar, trazer exemplos e práticas, para que os professores 
encontrem em tais fazeres subsídios para começarem a modificar suas ações nas salas de aula; o que não irá acontecer apenas pautando-se em teoria ou naquilo que "se deve fazer". Bitante (2016, p. 282) destaca que a "simples alfabetização digital é considerada não suficiente e [...] prioritária na formação do professor notadamente, [...] feita de forma isolada dos conceitos e epistemológicos, filosóficos e sociológicos que subjazem às Ciências da Educação".

Com isso, salienta-se o que Caliari, Zilber e Perez (2017, p. 249) apontam sobre as TIC, “considerado um processo que vai além de características e atributos, passa a ser visto como um fator institucional e social". Não se trata de simplesmente alfabetizar professores e alunos de maneira técnica referente às TIC, como colocam Kurtz, Vargas e Moura (2018). Mas sim, de trabalhar letramentos com os profissionais da educação. Alfabetizar diz respeito à parte estrutural e técnica, como aprender as "regras" de um sistema; letrar é mais, é a interpretação, é o refletir sobre essa linguagem e analisar aquilo que é disseminado por ela.

Considerando as colocações apontadas, finalizamos esta análise ressaltando que, de fato, para que novas práticas sejam formuladas, é preciso que se invista na formação contínua dos profissionais da educação. Por mais que a temática esteja em alta e já seja consenso entre academia e pesquisas, a sua articulação efetiva, nas salas de aula e currículo, consciente e crítico ainda não alcança os patamares almejados, tal afirmação pode ser balizada pela pesquisa de Kurtz et al. (2018, p. 1133), que demonstram que “em cursos de formação de professores, há pouquíssima articulação das TIC com o ensinar e aprender, e, quando isso ocorre, se dá de forma instrumental". Os autores investigaram a presença e a forma como as TIC aparecem em currículos de Licenciaturas (161 cursos) que possuem conceito 4 ou 5 de acordo com o site do MEC, de Universidades de 26 Estados do Brasil, e constataram que a presença destas ferramentas não ocorre de forma transversal nos currículos da educação brasileira.

Logo, as práticas pedagógicas que englobam as TIC ainda se configuram, em sua grande maioria, como tecnicistas. É neste sentido que afirmamos que os professores precisam estar em constante formação para adquirir habilidades para pensar sua ação, refletir e agir sobre todo seu contexto social e escolar, levando aos alunos às mesmas ações. Por isso, destacamos, como Imbernón (2010, p. 64), a importância de se propor 
novas metodologias adequadas à realidade social e que sejam do contexto dos alunos e que, portanto, considerem as TIC como ferramentas transversais em suas práticas pedagógicas. Principalmente, entendo-as como instrumentos que auxiliam com a abstração dos conhecimentos, em perspectiva tanto teórica, como prática e social, considerando a observação, o debate, a reflexão, o contraste de pontos de vista, a análise da realidade social.

Por isso, surge a necessidade de compreender os estudos de autores como Mishra e Koehler (2006), em relação a esta articulação, que desenvolveram o framework denominado Technological Pedagogical Content Knowledge (TPACK) (ou Conhecimento Tecnológico Pedagógico de Conteúdo). Tal quadro propõe que os processos de ensino e aprendizagem se deem a partir de uma espiral, iniciando a formação de professores por tecnologias mais simples e familiares, e depois, que seja trabalhada por instrumentos mais elaborados/complexos.

Esta espiral se baseia, nos três grandes eixos (tecnológico, pedagógico e conteúdo), que deveriam balizar os conhecimentos essenciais aos professores e se desenvolvem, a partir da intersecção de mais outras formas: Conhecimento de Conteúdo (CK - Content Knowledge); Conhecimento Pedagógico (PK - Pedagogical Knowledge); Conhecimento Tecnológico (TK - Technological Knowledge); Conhecimento tecnológico do conteúdo (TCK - Technological Content Knowledge); Conhecimento pedagógico do conteúdo (PCK - Pedagogical Content Knowledge), Conhecimento Pedagógico Tecnológico (TPK - Technological Pedagogical Knowledge) (KURTZ; VARGAS; MOURA, 2018).

O interessante deste framework, é justamente a proposição em assumir as TIC como um processo também pedagógico, logo, pode ser assumido como um quadro a ser trabalhado nos currículos de formação inicial e continuada de professores, em vista de modificar as práticas tradicionais salientadas. Deste modo, os professores podem incorporar as TIC no modelo educacional vigente, contribuindo na transformação do paradigma emergente; principalmente no entendimento de que se precisa resolver esse problema da educação tradicional que paira sob o século XXI, completando, assim, o ciclo da revolução científica do paradigma emergente. 


\section{CONCLUSÃO}

A partir do presente estudo, pudemos compreender que o paradigma tradicional de educação, presente até hoje, não consegue contemplar mais as questões cidadãs e humanas da vida dos sujeitos. Assim, os artigos analisados apontam que, nos dias atuais, se faz necessário o entendimento de que com o advento das tecnologias TIC, as ações, práticas e posturas, daqueles envolvidos na comunidade escolar, além do currículo como um todo, ofereçam uma formação mais ampla.

A análise dos artigos permitiu reconhecer que, em sua grande maioria, são recentes e poucos. São discussões teóricas de temas e reflexões relevantes, que condizem com os pressupostos apontados na discussão, demonstrando que um novo paradigma está em construção. No entanto, os artigos com discussões empíricas tratam de questionários, e não de aplicações pedagógicas com práticas, ou seja, são avaliações ou sobre a figura do professor e dos alunos ou das relações com as TIC. O que implica na falta de ações mais concretas em relação à construção de novas práticas que poderiam servir como exemplos de pesquisas, que extrapolam a teoria.

Por meio da análise também foi possível compreender que as TIC são ferramentas culturais essenciais na construção e articulação do novo paradigma, especialmente, na construção de uma educação mais igualitária, crítica, ética de sujeitos, que se formem autônomos e colaborem significativamente uns com os outros, a partir de interações cognitivas e interpessoais. Além de vislumbrar a importância das formações continuadas, em relação ao envolvimento com as TIC e metodologias outras, proporcionando o redimensionamento das práticas em sala de aula. É preciso que sejam proporcionadas formações com relação a esses temas, investindo naqueles que educam milhares de pessoas; investindo na reflexão, na criticidade, na formação humana integral e cidadã dos sujeitos - na educação de modo geral.

Por fim, sabemos que um paradigma pode demorar anos para se perpetuar, assim, salientamos a necessidade de discussões como as que foram postas neste trabalho, principalmente para se ter o entendimento e a compreensão da seriedade que é falar em paradigmas educativos e suas concepções. O intuito não é esgotar o tema de pesquisa 
aqui discutido, mas demonstrar um ponto de vista sobre a importância e a influência das TIC, na educação, na constituição de um novo paradigma educacional.

\section{REFERÊNCIAS}

BEHRENS, M. A. O Paradigma Emergente e a Prática Pedagógica. 5. ed. Petrópolis: Vozes, 2013.

BEHRENS, M. A. Projetos de aprendizagem colaborativa num paradigma emergente. In.: SIMAS, R. R. L.; BEHRENS, M. A. Paradigmas pedagógicos contemporâneos: tecendo práticas diferenciadas e inovadoras. Dialogia, São Paulo, n. 31, p. 179-186, jan./abr. 2019.

FREIRE, P. Pedagogia da autonomia: saberes necessários à prática educativa. São Paulo: Paz e Terra, 2008.

IMBERNÓN, F. Formação continuada de professores. Porto Alegre: ArTmed, 2010.

KUHN, T. S. A Estrutura das revoluções científicas. 5. ed. São Paulo: Editora Perspectiva, 1998.

KURTZ, F. D.; VARGAS, R. S.; MOURA, R. Tecnologias e formação de professores de línguas: além de uma perspectiva técnica. Afluente, v. 3, p. 2225-3441, 2018.

KURTZ, F. D. S.; VARGAS, R. S.; MOURA, R. O.; SILVA, D. Presentes em documentos oficiais, ausentes na formação docente: indícios acerca de um esvaziamento teórico envolvendo TIC e a formação de professores no Brasil. Technology Enhanced Learning. Anais... V Congresso Internacional TIC e Educação, Lisboa, 2018.

MACEDO, E.; LOPES, A. C. Teorias do currículo. São Paulo: Ed. Cortez, 2011.

MISHRA, P.; KOEHLER, M. J. Technological Pedagogical Content Knowledge: a framework for teacher knowledge. Teachers College Report, p. 1017-1054, 2006.

MORAES, M. C. O paradigma educacional emergente: implicações na formação do professor e nas práticas pedagógicas. Em Aberto, Brasília, v. 16, n.70, p. 57-69, abr./jun. 1996.

MORAES, R. Uma tempestade de luz: a compreensão possibilitada pela análise textual discursiva. Ciência e Educação, v.9, n. 2, p.191-211, 2003

MORAES R.; GALIAZZI, M. C. Análise Textual Discursiva. Ijuí: Editora Unijuí, 2013. 
MORAN, J. M.; MASETTO, M. T.; BEHRENS, M. A. Novas tecnologias e mediação pedagógica. São Paulo: Papirus, 2000. (Coleção Papirus Educação).

OSÓRIO, T.; STOLL, V. G.; MARTINS, M. M. Investigação na Formação Inicial: concepções sobre as TIC e a Energia no Curso de Licenciatura em Ciências da Natureza. Revista Insignare Scientia - RIS, v. 2, n. 2, p. 22-36, 16 set. 2019.

SIMAS, R. R. L.; BEHRENS, M. A. Paradigmas pedagógicos contemporâneos: tecendo práticas diferenciadas e inovadoras. Dialogia, São Paulo, n. 31, p. 179-186, jan./abr. 2019.

WERTSCH, J. V. Computer mediation, PBL, and dialogicality. Distance Education, v. 23, no. 1, 2002. 